\title{
Erratum to: Polynomial Regression with Response Surface Analysis: A Powerful Approach for Examining Moderation and Overcoming Limitations of Difference Scores
}

\author{
Linda Rhoades Shanock • Benjamin E. Baran • \\ William A. Gentry • Stacy Clever Pattison • \\ Eric D. Heggestad
}

Published online: 9 August 2013

(C) Springer Science+Business Media New York 2013

\section{Erratum to: J Bus Psychol (2010) 25:543-554 DOI 10.1007/s10869-010-9183-4}

Please note there was an error in the standard error formula for the significance test for $a_{4}$ (the surface that represents the curvature of the $\mathrm{X}=-\mathrm{Y}$ as related to $\mathrm{Z}$ line) in both the formula presented in our article and in the associated Excel file. We corrected it in the table to the right which contains the full set of formulas for $a_{1}$ through $a_{4}$. We also corrected it in the spreadsheet that you can download to conduct and graph the analyses described in the original paper. To download a copy of the Excel spreadsheet for your use, please visit the following website www.springer. com/psychology/community+psychology/journal/10869. When you get to the website, go to the section on the right

The online version of the original article can be found under doi:10.1007/s10869-010-9183-4.

L. R. Shanock $(\bowtie) \cdot$ E. D. Heggestad

UNC Charlotte Psychology Department, University of North

Carolina at Charlotte, Charlotte, NC, USA

e-mail: 1shanock@uncc.edu

E. D. Heggestad

e-mail: edhegges@uncc.edu

B. E. Baran

UNC Charlotte Organizational Science Program, University of North Carolina at Charlotte, Charlotte, NC, USA

e-mail: bebaran@uncc.edu

\section{W. A. Gentry}

Center for Creative Leadership, Greensboro, NC, USA

e-mail: gentryb@ccl.org

S. C. Pattison

U.S. Office of Personnel Management, Washington, DC, USA

e-mail: Stacy.Pattison@opm.gov
Table 4 Formulas for calculating the significance tests of the surface values $\left(a_{1}\right.$ through $\left.a_{4}\right)$

\begin{tabular}{lll}
\hline Variable & Equation \\
\hline$a_{1}$ & $t=\frac{a_{1}}{\sqrt{\left(S E^{2} b_{1}+S E^{2} b_{2}\right)+2 \operatorname{COV} b_{1} b_{2}}}$ \\
$a_{2}$ & $t=\frac{a_{2}}{\sqrt{\left(S E^{2} b_{3}+S E^{2} b_{4}+S E^{2} b_{5}\right)+2 \operatorname{COV} b_{3} b_{4}+2 \operatorname{cov} b_{4} b_{5}+2 \operatorname{cov} b_{3} b_{5}}}$ \\
$a_{3}$ & $t=\frac{a_{3}}{\sqrt{\left(S E^{2} b_{1}+S E^{2} b_{2}\right)-2 \operatorname{COV} b_{1} b_{2}}}$ \\
$a_{4}$ & $t=\frac{a_{4}}{\sqrt{\left(S E^{2} b_{3}+S E^{2} b_{4}+S E^{2} b_{5}\right)-2 \operatorname{COV} b_{3} b_{4}+2 \operatorname{cov} b_{3} b_{5}-2 \operatorname{cov} b_{4} b_{5}}}$
\end{tabular}

Note. For the formulas listed above, recall from Table 2 that $a_{1}=\left(b_{1}+b_{2}\right)$ where $b_{1}$ is beta coefficient for perceived supervisor support (PSS) and $b_{2}$ is beta coefficient for perceived organizational support (POS). ${ }^{\mathrm{c}} a_{2}=\left(b_{3}+b_{4}+b_{5}\right)$ where $b_{3}$ is beta coefficient for PSS squared, $b_{4}$ is cross product of PSS and POS, and $b_{5}$ is beta coefficient for POS squared. ${ }^{\mathrm{d}} a_{3}=\left(b_{1}-b_{2}\right) .{ }^{\mathrm{e}} a_{4}=\left(b_{3}-b_{4}+b_{5}\right)$. Also recall that the BCOV subcommand in the SPSS syntax will provide the covariances needed for the " $2 \mathrm{cov}$ " (two times the covariance) terms listed above

that says 'For Authors and Editors'. Mouse over and click on the down arrow and you will see the Response Surface Analysis Excel sheet. 